\title{
Batalha das biografias na arena midiática da democracia: análise de enquadramento da deliberação mediada jornalística
}

Paulo Ferracioli e Carla Rizzotto

\section{Resumo}

0 objetivo deste artigo é analisar como os

enquadramentos noticiosos relacionam-se com 0 potencial deliberativo de uma cobertura jornalística. Como objeto, optou-se pelo debate sobre a publicação de biografias não autorizadas, em que se estabeleceu uma discussão sobre qual direito deveria prevalecer, se a liberdade de expressão do biógrafo ou o direito à intimidade do biografado. 0 corpus engloba 56 matérias de Folha de S. Paulo, 0 Globo e 0 Estado de S. Paulo. Como metodologia, foram adotados enquadramentos genéricos - conflito, interesse humano, consequências econômicas, moralidade e responsabilidade -, associados com categorias de potencial deliberativo - inclusividade, civilidade, provimento de razões, responsividade e orientação para o bem comum. As relações entre enquadramentos apontam que o enquadramento de responsabilidade esteve relacionado com caraterísticas negativas.

\section{Palavras-Chave}

Enquadramento noticioso. Deliberação mediada. Biografias.

\section{Paulo Ferracioli}

Doutorando no Programa de Pós-Graduação em Ciência Política da Universidade Federal do Paraná - UFPR, Curitiba, Paraná, Brasil. Mestre em Comunicação pela UFPR. E-mail: ferracioli.paulo@gmail.com https://orcid.org/0000-0001-9355-3365

\section{Carla Rizzotto}

Doutor em Comunicação e Linguagens pela Universidade Tuiuti do Paraná, Brasil. Professor Colaborador da Universidade Federal do Paraná - UFPR, Curitiba, Paraná, Brasil. E-mail: carla_rizzotto@yahoo.com.br https://orcid.org/0000-0002-0847-4660

\section{Introdução}

As biografias consolidaram-se como sucesso de vendas no Brasil, com a contribuição relevante de três jornalistas: Ruy Castro, Fernando Morais e Jorge Caldeira. Seus escritos - dentre os quais é possível citar Olga e Chatô, de Morais, e $O$ anjo pornográfico e Estrela Solitária, de Castroforam sucesso de venda no início dos anos 1990. Do mesmo modo, firmaram o nome de ambos os autores como referências na área até os dias atuais, uma vez que "seus livros combinavam pesquisa meticulosa e narrativa carismática; apesar de longos e bem documentados, garantiam leitura cativante" (FRIAS FILHO, 2011, p. 4).

Essas obras, no entanto, não estavam livres de disputas, especialmente entre os biógrafos e os biografados. 0 imbróglio judicial brasileiro mais famoso, que exemplifica bem esse embate, deu-se entre Roberto Carlos e a Editora Planeta, responsável pela publicação da biografia Roberto Carlos em Detalhes, escrita por Paulo César de Araújo. A pedido do cantor, o juízo da $20^{\text {a }}$. Vara Cível do Rio de Janeiro decidiu em caráter liminar 
pela suspensão das vendas da biografia não autorizada. Houve acordo posterior entre 0 biografado e a editora, de forma que a obra foi retirada do mercado, e esse processo em trâmite foi extinto.

Esses embates entre as posições antagônicas a respeito dos limites das biografias, que foram recorrentes nas disputas judiciais nas últimas décadas, tiveram amplo espaço nas páginas dos periódicos nacionais em outubro de 2013, a partir de uma manifestação inicial do grupo Procure Saber, a partir da qual se seguiu uma ampla discussão nos veículos impressos entre variados atores. Vários argumentos foram apresentados por diversos atores, mas se centralizaram em dois grupos de direitos em discussão: a liberdade de expressão do autor da obra biográfica e a privacidade dos retratados.

Ambos os direitos são protegidos pelo texto constitucional brasileiro, de modo que se instaurou uma colisão entre valores relevantes para a sociedade.

0 trabalho dos biógrafos é uma forma de exercer a liberdade de expressão e a liberdade de informação. Ao pesquisarem inúmeros dados e publicarem uma obra cujo conteúdo é reconstruir a trajetória de vida de algum indivíduo, esses profissionais valem-se da liberdade de manifestação de ideias e de pensamentos. A edição irrestrita de livros é um fator que contribui para a sociedade democrática. Por outro lado, as pessoas notórias que são retratadas nas biografias têm direitos à privacidade, à honra e à imagem, que podem ser ofendidos pela publicação dessas obras.

É preciso levar em conta, no entanto, que a jurisprudência vem entendendo a liberdade de expressão como um valor social. Limitá-la não representaria apenas uma desvantagem a um indivíduo isolado, mas uma perda para a sociedade como um todo. 0 desenvolvimento dos grupos sociais depende da circulação de ideias e informações no maior número possível. Ademais, 0 cidadão tem 0 direito de ser informado, de receber as informações que julgue necessárias para seu desenvolvimento. Contudo, a intimidade dos biografados é um campo protegido juridicamente que certos textos biográficos podem invadir. Desconsiderando os fatos que o próprio sujeito expôs publicamente e com cuja divulgação ele consentiu, há certos detalhes da vida privada que o biografado tem interesse legítimo em não expor. Esse embate, portanto, pode ser entendido como um confronto político, ou seja, uma disputa em que um grupo pleiteia uma reivindicação que configura uma ameaça para outros setores da sociedade (TARROW, 1997). Essa ação contenciosa ocorre de diversas formas, sendo o posicionamento público, especialmente por meio da imprensa, uma maneira de resistência registrada com frequência.

E foi desse embate que partiu o questionamento que orienta esta pesquisa: de que maneira os enquadramentos jornalísticos afetaram 0 potencial deliberativo da cobertura sobre 0 tema 
das biografias? 0 objetivo geral da presente pesquisa, portanto, é compreender como os enquadramentos jornalísticos estão associados com a capacidade deliberativa da cobertura midiática do caso "batalha das biografias".

Sob a ótica deliberativa, a mídia, e mais especificamente 0 jornalismo, desempenham um papel importante no sistema deliberativo, através, por exemplo, do fornecimento de opinião plural e da promoção de um debate de qualidade (MARQUES, MIOLA, 2010). Analisar como a cobertura das biografias se comportou em termos do seu potencial deliberativo, portanto, permite averiguar a contribuição democrática do jornalismo nessa disputa e pode, inclusive, apontar parâmetros a serem aprofundados e comprovados em pesquisas com a intenção de sedimentar as concepções dessa área de estudo.

Assim, o presente artigo está estruturado da seguinte forma: a seção seguinte traz uma revisão de literatura sobre 0 papel da deliberação e, em especial, da mídia no debate público. Em seguida, será apresentada a metodologia da análise de enquadramento noticioso, com o intuito de precisar os conceitos utilizados na pesquisa. A próxima seção traz a análise realizada com as 56 notícias que compõem o corpus da pesquisa. Por fim, é feita a discussão dos resultados, e algumas considerações finais são tecidas.

\section{Mídia e deliberação}

As relações entre meios de comunicação e a esfera pública foram sempre próximas. Tendo em vista a dinâmica desempenhada pelos media, que são capazes de selecionar as mensagens a serem distribuídas, influenciar agendas e enquadrar os assuntos, seu papel para a arena deliberativa é relevante e merece atenção (HABERMAS, 2006).

Habermas (1991) percebeu nos oligopólios dos meios de comunicação um empecilho para 0 desenvolvimento da esfera pública. Enquanto, no período iluminista, as instituições de imprensa conseguiam escapar da dominação do poder público por estarem na mão dos particulares, a sua passagem para a mão de grupos economicamente concentrados acabou por ameaçar as funções críticas que se esperavam da imprensa. 0s meios de comunicação seriam responsáveis por promover uma despolitização da esfera pública, pela mistura de informação e entretenimento, abordagem episódica dos acontecimentos e ausência de contextualização adequada.

Autores deliberacionistas tradicionais, como Guttman e Thompson (2004), chegaram a afirmar que os meios de comunicação de massa não são amigáveis à deliberação, o que impediria os cidadãos de se prepararem para os processos democráticos. A deliberação mediada seria dificultada, ainda, pela ausência de interação face a face entre os cidadãos que precisam chegar a uma decisão, além da ausência de reciprocidade 
entre os agentes com direito a fala e os receptores do discurso midiático (HABERMAS, 2006).

Essa concepção negativa da relação entre esfera pública e meios de comunicação, contudo, foi rebatida. Visões mais otimistas apontam que a mídia pode ser um locus para a deliberação (SIMON, XENOS, 2000). Ainda que "os meios de comunicação não possam ser entendidos como uma 'esfera pública' em si, eles disponibilizam expressões, matérias, discursos, eventos para 0 conhecimento comum" (MAIA, 2008, p. 18). Dito de outro modo, a mídia não é a esfera pública, mas é capaz de estruturá-la através de um diálogo público generalizado.

A intenção da deliberação mediada é garantir que os indivíduos exponham-se a posições conflitantes e possam avaliá-las para alcançar seus próprios julgamentos (GASTIL, BLACK, 2007). A mídia, portanto, é um dos espaços encontrados pela esfera pública para reverberar a discussão dos problemas políticos. Os meios de comunicação são elementos essenciais porque não há outro fórum que tenha tamanho alcance e repercussão (MAIA, 2008). A deliberação nesses casos pretende que, além da produção de decisões políticas, haja um aumento na informação disponível para os cidadãos (seja em quantidade, sejaem qualidade), para que as políticas sejam mais efetivas e que se alcance maior accountability sobre os governantes (MIOLA, 2012).

Embora não seja 0 único vetor a possibilitar a interação discursiva nas sociedades democráticas atuais, os meios de comunicação são responsáveis por garantir, pelo menos, um "repositório informacional minimamente adequado" (MARQUES, MIOLA, 2010). A partir disso, os cidadãos podem compreender melhor os acontecimentos, balancear os argumentos apresentados e, assim, motivar justificadamente uma decisão. Mais do que cidadãos beminformados, caberia à mídia permitir que se desenvolvam "cidadãos interpretantes" (PORTO, 2003), que sejam capazes de construir sentidos a partir do que lhes é apresentado.

Necessário esclarecer que não se cogita aqui a ideia de que 0 potencial deliberativo do espaço midiático seja equivalente àquele de uma discussão presencial entre cidadãos, mas de reconhecer que o espaço midiático é um lugar privilegiado para trocas argumentativas embasadas nos moldes deliberativos.

\section{É possível, portanto, pensar em algumas} características próprias que caracterizam 0 processo de deliberação mediada. A questão da acessibilidade é um aspecto crucial na mídia, pois os jornalistas, ao determinarem quem tem acesso a esse espaço e de que maneira ele será valorizado, permitem legitimar e hierarquizar determinadas estruturas de poder (MAIA, 2008). Isso motivou a escolha do critério de inclusividade para analisar a deliberação na cobertura das biografias.

A utilização de argumentos também é elemento típico do paradigma deliberativo que precisa 
estar presente na deliberação mediada, ainda que sejam veiculados apenas trechos das argumentações defendidas pelos envolvidos nos debates. Isso porque "os jornalistas e comentaristas podem fornecer 'atalhos cognitivos', destacando as principais posições e as linhas argumentativas em disputa, a fim de que essas se tornem mais facilmente acessíveis à audiência" (MAIA, 2008, p. 50).

A responsividade é outro critério de avaliação da deliberação mediada, ao permitir que se diagnostique de que maneira os participantes respondem às indagações dos outros, construindo um diálogo. Em se tratando de cobertura jornalística, essa interação discursiva pode surgir ao longo dos textos, conforme 0 tema vai sendo exposto pelas notícias. Ainda assim, é possível que os participantes se recusem a refletir sobre as posições contrárias, o que os torna fechados no seu próprio universo podendo até mesmo influenciar negativamente a credibilidade desses atores políticos (MAIA, 2008).

A ideia de reciprocidade, aqui, não pode ser vista como uma questão de altruísmo ou de harmonia ao lidar com conflitos, sob pena de se entender erroneamente 0 intercâmbio de ideias necessário para esse processo (MENDONÇA, FREITAS, OLIVEIRA, 2014). A reciprocidade, inclusive, pode ser percebida a partir de duas características: a direta, que consiste na troca direta de razões entre os participantes do debate (foi essa a perspectiva adotada para a categorização das notícias realizada), e uma reciprocidade discursiva, cujo foco são os choques de discurso e consiste na rede discursiva que se estabelece ao longo do processo deliberativo (MENDONÇA, FREITAS, OLIVEIRA, 2014).

A visibilidade é outro elemento essencial para a deliberação permitida pela mídia, mas pode também ser um empecilho para uma discussão coerente. Ao mesmo tempo em que a discussão visível permite que os discursos possam ser verificáveis, ela impede que alguns elementos caros à deliberação aconteçam, como a reversão de opiniões e 0 convencimento, em razão de um possível constrangimento (MIOLA, 2012).

Ainda na seara da publicidade, é possível pensar em um outro aspecto, 0 da discutibilidade, que se apoia na premissa de que o debate sobre os assuntos pode ser uma maneira de fortalecer a relevância de determinadas questões perante 0 público (MIOLA, 2012). A deliberação mediada, nesse ponto, pode impulsionar esse aspecto, uma vez que propicia condições para que 0 debate seja amplificado.

Em suma, os meios de comunicação podem ser apontados como atores importantes no processo deliberativo. Em sociedades populosas, os jornalistas cumprem melhor a tarefa de disseminar as informações para o maior número de pessoas. Dessa forma, "mediated deliberation can be highly public and successful, but only if decentralization produces a variety of opinions 
and the division of political labor is capable of producing suficient cognitive diversity and mutual criticism" "PAGE, 1995, apud BOHMAN, 1998, p. 421).

0 ponto principal é compreender que certos enquadramentos podem favorecer a deliberação democrática, ao mesmo tempo que outros aspectos, tais como a busca por audiência, 0 desinteresse em afrontar grupos políticos e a opção pelo entretenimento podem se sobrepor a esses frames desejáveis (MARQUES, MIOLA, 2010). Já foi apontado, inclusive, que os veículos midiáticos tendem a construir enquadramentos macro nos quais concentram as principais perspectivas discursivas sobre os temas em debate (MARQUES, 2010).

Entender a atuação dos meios de comunicação nesse intrincado jogo deliberativo, portanto, passa por analisar quais são os enquadramentos disponibilizados pela mídia e de que modo interferem na qualidade da deliberação.

\section{Enquadramentos e deliberação}

Pensar a correlação entre enquadramento noticioso e deliberação é tarefa que já vem sendo levada a cabo pelos estudos da área. A cobertura jornalística promove diversos frames - compreendendo-os sob o aspecto deliberativo - que são postos em competição para que, ao final do processo, algum deles tenha emergido como vencedor (SIMON, XENOS, 2000). Ademais, o debate nos meios de comunicação pode ter seu campo interpretativo delimitado pelos enquadramentos utilizados, 0 que influencia a maneira como as questões têm seu significado construído (MAIA, 2009).

É preciso fazer, inicialmente, um esclarecimento sobre o conceito de enquadramento. Contando com extensa pesquisa na área (a saber, ENTMAN, 1993; GAMSON, MODIGLIANI, 1987; PORT0, 2004), os enquadramentos podem ser compreendidos como uma ideia organizadora central do texto que permite que certos aspectos sejam postos em relevância em detrimento de outros. Tal noção tem ampla aceitação nos estudos de comunicação e política, especialmente na pesquisa brasileira (como exemplo, VIMIEIR0, MAIA, 2011). Uma extensa corrente de pesquisa procura em seus estudos a influência na população dos enquadramentos adotados pela mídia. Seja através do uso de grupos focais, seja de amplos surveys com a população, pesquisadores já sedimentaram entendimentos sobre o impacto dos frames nos cidadãos (CHONG, DRUCKAM, 2007). É 0 caso de Druckman e Nelson (2003), que apontaram que a deliberação entre os cidadãos sobre temas públicos enfraqueceu a influência de elite frames, ou seja, dos enquadramentos fornecidos 
por setores da elite social, em grupos diversos.

Quando os indivíduos envolviam-se em discussões tendo sido expostos apenas aos mesmos frames dominantes, não havia grandes alterações mesmo após os debates. No entanto, conversações entre indivíduos que foram expostos a enquadramentos conflitantes de um evento eliminaram as influências prévias e permitiram debates mais amplos, com reversão de pensamentos prévios.

Há, ainda, estudos nacionais que utilizaram os enquadramentos como maneira de compreender as mudanças dos discursos ocorridas ao longo do processo deliberativo (MENDONÇA, FREITAS, OLIVEIRA, 2014). Para esse intuito, os frames servem para mostrar o diálogo entre os argumentos das partes envolvidas, com suas modificações e tensionamentos conforme 0 debate avançava.

A linha pretendida na presente pesquisa, no entanto, busca relacionar os enquadramentos midiáticos com o sucesso da deliberação, na qual há pouca produção acadêmica (RINKE et al, 2013). Cottle e Rai (2006), por exemplo, investigaram os enquadramentos em notícias televisivas, já delineando que a pluralidade dos frames apresentados contribuía para diferentes possibilidades de entendimento do público sobre os assuntos tratados e, consequentemente, para 0 aprofundamento da democracia. Agrupados em dois grandes grupos possíveis de frames, que foram nomeados de conflito e de consenso, dez possíveis enquadramentos foram identificados: dominant, contest, contention, campaigning, investigative, community service, collective interests, cultural recognition e mythic tales.

Os autores optaram por não discutir se um enquadramento era intrinsecamente melhor ou pior que outro, pois cada um deles acrescentava uma visão à discussão. Era a arquitetura comunicativa complexa das notícias dos telejornais, que fornecia um repertório de frames diferentes e identificáveis aos telespectadores e permitia a elaboração pública dos grandes temas e sua discussão (COTTLE, RAI, 2006).

Em artigo que pretendia relacionar os enquadramentos com aspectos deliberativos na cobertura jornalística sobre eleições, Rinke et al. (2013) traçaram algumas hipóteses. A primeira previa que coberturas em que houvesse o enquadramento strategic game apresentariam menores índices de civilidade do que naquelas nas quais não houvesse tal enquadramento.

As outras presunções dos cientistas eram de que a presença do strategic game frame também acarretaria pouca responsividade e provimento de razões. Essas três primeiras hipóteses foram confirmadas pelos resultados encontrados, que demonstraram uma associação nas frequências entre os enquadramentos e as características.

As outras três hipóteses diziam respeito ao enquadramento de contestação: esperava-se que, quando ele estivesse presente, seriam 
encontrados níveis maiores de inclusividade e provimento de razões, porém índices mais baixos no quesito civilidade. Já nesse aspecto, os dados não confirmaram apenas a primeira dessas presunções: não houve correlação visível entre 0 enquadramento de contestação e 0 nível de inclusividade da cobertura jornalística.

As outras duas correlações, no entanto, foram confirmadas pelos dados empíricos coletados naquelas notícias.

A seção seguinte será dedicada a expor em profundidade quais os enquadramentos adotados, bem como as características deliberativas que serão avaliadas pela análise.

\section{Procedimentos metodológicos e resultados}

As matérias aqui analisadas foram coletadas ao longo do mês de outubro de 2013, nos três quality papers ${ }^{2}$ de maior circulação no país, a saber: Folha de S. Paulo, 0 Globo e 0 Estado de S. Paulo, nessa ordem, conforme apontam os dados do Instituto Verificador de Comunicação (IVC) em 2015. Foi nesse mês específico que os jornais mais abordaram a questão, com um número de matérias muito maior do que nos outros meses do mesmo ano ou dos anos seguintes.
Optou-se pela utilização de cinco

enquadramentos genéricos, baseados naqueles primeiramente apresentados por Semetko e Valkenburg (2000) e, depois, aperfeiçoados pela literatura, como em Guenduez, Schedler e Ciocan (2016): (1) atribuição de responsabilidade, que enxerga o problema a partir do papel que desempenharia o governo para resolvê-lo; (2) interesse humano, no qual um personagem é destacado e vira 0 foco das atenções ao longo do texto; (3) conflito, com ênfase em abordar questões públicas por meio da disputa entre indivíduos específicos; (4) moralidade, quando o problema é visto predominantemente por um lado moral, ético ou religioso; e (5) consequências econômicas, quando a matéria se detém num olhar econômico para o problema posto.

A tabela 1 mostra os primeiros resultados da análise, associando os enquadramentos às cinco características deliberativas que predominaram em cada um deles.

Ressalte-se que, sobre 0 enquadramento da moralidade, a presente pesquisa não permite o estabelecimento de conclusões, visto que seu aparecimento em apenas uma notícia, sem nenhuma característica deliberativa exclusiva, impede um entendimento melhor sobre esseframe. 
Tabela 1: Relação entre os enquadramentos e as características deliberativas predominantes

\begin{tabular}{c|c|c|c|c|c}
\hline $\begin{array}{c}\text { Enquadramentos } \\
\text { / características } \\
\text { deliberativas }\end{array}$ & Inclusividade & Civilidade & Responsividade & Provimento de razões & $\begin{array}{c}\text { Orientação para } \\
\text { o bem comum }\end{array}$ \\
\hline Conflito (20) & $\begin{array}{c}\text { Biógrafos } \\
(12)-60 \%\end{array}$ & $\begin{array}{c}\text { Respeito } \\
\text { implícito } \\
(17)-85 \%\end{array}$ & $\begin{array}{c}\text { Menção e degradação } \\
\text { da posição contrária } \\
(12)-60 \%\end{array}$ & $\begin{array}{c}\text { Posição não justificada } \\
(7)-\text { Forte justificação } \\
(7)-35 \%\end{array}$ & $\begin{array}{c}\text { Neutra } \\
(8)-40 \%\end{array}$ \\
\hline $\begin{array}{c}\text { Responsabilidade } \\
(16)\end{array}$ & $\begin{array}{c}\text { Políticos e STF } \\
(12)-75 \%\end{array}$ & $\begin{array}{c}\text { Respeito } \\
\text { implícito } \\
(16)-100 \%\end{array}$ & $\begin{array}{c}\text { Sem menção a outros } \\
\text { argumentos (9) } \\
-56 \%\end{array}$ & $\begin{array}{c}\text { Posição não justificada } \\
(6)-\text { Relação causal } \\
(6)-37 \%\end{array}$ & $\begin{array}{c}\text { Neutra } \\
(13)-81 \%\end{array}$ \\
\hline $\begin{array}{c}\text { Interesse humano } \\
(15)\end{array}$ & $\begin{array}{c}\text { Artistas e } \\
\text { familiares } \\
(11)-73 \%\end{array}$ & $\begin{array}{c}\text { Respeito } \\
\text { implícito } \\
(10)-66 \%\end{array}$ & $\begin{array}{c}\text { Mera menção a } \\
\text { outros argumentos } \\
(7)-46 \%\end{array}$ & $\begin{array}{c}\text { Posição não justificada } \\
(5)-\text { Forte justificação } \\
(5)-33 \%\end{array}$ & $\begin{array}{c}\text { Orientação } \\
\text { individual ou para } \\
\text { grupo (6) - 40\% }\end{array}$ \\
\hline $\begin{array}{c}\text { Weconômico (4) } \\
\text { Biógrafos } \\
(4)-100 \%\end{array}$ & $\begin{array}{c}\text { Respeito } \\
\text { implícito } \\
(4)-100 \%\end{array}$ & $\begin{array}{c}\text { Menção e degradação } \\
\text { da posição contrária } \\
(3)-75 \%\end{array}$ & $\begin{array}{c}\text { Relação causal } \\
(3)-75 \%\end{array}$ & $\begin{array}{c}\text { Orientação } \\
\text { individual ou para } \\
\text { grupo (3) - 75\% }\end{array}$ \\
\hline
\end{tabular}

Fonte: elaboração própria

\section{Conflito: destaque para degradação da posição contrária}

Quanto à inclusividade, é interessante destacar que, das poucas matérias em que foi ouvido o máximo de três grupos diferentes (não houve nenhuma matéria com quatro ou mais grupos retratados), $80 \%$ encaixaram-se no enquadramento conflito. Pensar o tema como um embate, assim, permitiu que os textos trouxessem mais vozes da questão e tornassem mais plural os pontos de vista mostrados.
0 grupo mais ouvido foi o de biógrafos (12 matérias), acompanhado dos artistas e familiares (10 matérias), o que demonstra que o conflito foi construído entre esses dois grupos. Matérias como "Chico pede desculpas por negar que deu entrevista a biógrafo"3 e "Biógrafo do Rei desmente Chico com fotos e gravações"4 só dão expressão para os biógrafos e biografados, pois ancoram-se nas disputas que foram surgindo entre os grupos.

Esse frame apresentou, na variável civilidade, um tom de respeito implícito em quase todas 
as matérias: 17 das 20. Ainda que essa característica esteja presente também em todos os enquadramentos analisados, o que aponta para um traço padrão dessa cobertura jornalística no todo, a sua predominância ajuda a negar uma possibilidade que oframe de conflito poderia gerar: a ocorrência frequente de palavras desrespeitosas.

Mesmo assim, cabe citar que o conflito foi um dos únicos enquadramentos que permitiu um tom diferente, qual seja, o de respeito explícito. Por focar 0 enfrentamento entre as partes, ainda que tenham proliferado momentos em que prevaleceu a neutralidade entre os participantes, houve textos em que a polidez foi destacada.

No que diz respeito à responsividade, esse enquadramento concentrou a maior parte das matérias em que havia menção e degradação da posição contrária: 12 das 20 matérias. Desse dado, é possível perceber que as matérias que continham oframe conflito ressaltaram falas dos personagens que atacavam os adversários.

Já no aspecto do provimento de razões, houve um equilíbrio entre três categorias: posição não justificada e forte justificação, com sete aparições cada e relação causal, com seis. A justificativa com diferentes razões, no entanto, foi rara nesse enquadramento de conflito: só uma aparição em todo o conjunto. Por 0 conflito ter sido destacado ao longo da matéria, não havia empenho em conceder espaço para que os argumentos fossem apresentados e desenvolvidos de maneira extensa. Houve, assim, a sobreposição da discussão sobre o conteúdo.

\section{A orientação para o bem comum foi}

um aspecto ignorado pelas notícias de enquadramento conflito, que se mostraram predominantemente neutras. As discussões personalizadas davam pouca margem a reflexões sobre os afetados pelas questões debatidas. Há exceções, como na matéria "Impedir biografias é censura, diz Ruy Castro", em que 0 escritor mencionado no título defende seu posicionamento por levar em conta que "as próximas gerações correm risco de não conhecerem detalhes da vida e trajetória de importantes personagens da nossa história".

0 enquadramento conflito, que foi 0 predominante nas matérias analisadas, permitiu a aparição de respeito explícito, mas ao mesmo tempo foi oframe dominante da menção e degradação da posição contrária. Além disso, houve pouco espaço para justificativas com diferentes razões, bem como para uma discussão voltada para a coletividade. 


\section{Responsabilidade: prevalência de fontes oficiais e ausência de menção a outros argumentos}

0 enquadramento da responsabilidade concedeu voz quase que exclusivamente aos membros das autoridades estatais, fossem eles parlamentares, ministros de Estado ou ministros do Supremo Tribunal Federal, presentes em 12 das 16 notícias. Artistas e biógrafos, que eram predominantes no enquadramento conflito, aqui são raramente ouvidos (só aparecem em duas matérias cada).

Esse enquadramento, no entanto, não atinge os critérios ideais de inclusividade por permitir que apenas um grupo seja noticiado: foram 12 matérias em que apenas um grupo foi ouvido, sem apresentar o debate que fortalece a deliberação e que consiste em uma prática jornalística das mais arraigadas, que é a de ouvir os dois lados da notícia.

Na civilidade, houve a aparição unânime de respeito implícito. Sabendo que era raro que grupos de visão oposta fossem focados nas mesmas matérias, é coerente que não apareçam menções de desrespeito ou respeito, uma vez que era raro haver a menção ao interlocutor na notícia. 0 empate entre posição não justificada e relação causal, com 6 aparições cada na variável provimento de razões, é mais um reforço da ausência de debate consistente nas matérias com 0 enquadramento responsabilidade. Em "Projeto de lei está parado há seis meses" deputados e o cantor ouvidos apenas relatam o que eles entendem ser a melhor saída, sem, contudo, apresentar a justificativa. Frágil, portanto, é 0 alcance deliberativo dessa matéria, pois não permite que o público leitor conheça argumentações diferentes e possa construir sua visão, como pretende idealmente 0 processo de deliberação mediada. É uma demonstração de que não há preocupação com os posicionamentos adversos, que são simplesmente negligenciados (MAIA, 2008).

No aspecto da orientação para o bem comum, a neutralidade também foi predominante, tal como no frame conflito, mas houve espaço para exposição de interesses voltados para 0 particular, até mesmo de parlamentares, como em "Câmara tentará votar hoje projeto que libera biografias"7, em que o deputado federal Lucio Vieira Lima manifesta-se contra as biografias com 0 argumento de evitar que as pessoas leiam mentiras sobre ele.

Em suma, o enquadramento responsabilidade teve destaques negativos, especialmente em dois

Projeto de lei está parado há seis meses, 0 Estado de S. Paulo, 16/10/2013.

Câmara tentará votar hoje projeto que libera biografias, 0 Globo, 23/10/2013. 
pontos. Na inclusividade, concedeu espaço quase exclusivo aos atores ligados ao Estado, sem ouvir outros participantes que poderiam acrescentar contribuições. Ainda, na responsividade, falhou ao apresentar matérias nas quais não havia sequer menção ao argumento da parte contrária, o que impossibilita a troca argumentativa que é a essência da deliberação mediada.

\section{Interesse humano: prevalecimento da orientação voltada para 0 individual}

0 grupo mais destacado nesses textos foi o dos artistas e familiares, haja vista que o foco de interesse eram histórias episódicas de artistas famosos e a relação que estabeleciam com suas biografias. Quase metade das matérias trazia apenas um grupo (em cinco delas, esse grupo único era o dos artistas familiares), o que é um critério negativo para a inclusividade, pois impede a circulação das vozes.

No aspecto da civilidade, mais uma vez predominou o respeito implícito, em 10 das 15 matérias desse frame. Porém, o que pode ser destaque nesse ponto é que, ao lado do conflito, 0 interesse humano foi 0 enquadramento que permitiu que as outras categorias de civilidade, que são o desrespeito e o respeito explícito, aparecessem na cobertura.
Na responsividade, 0 prevalecimento da mera menção a outros argumentos indica que já era estabelecido um diálogo entre os envolvidos, ainda que sem 0 desenvolvimento de contraargumentação. Foi nesse enquadramento que surgiram as outras ocorrências da degradação do argumento contrário. A personalização do debate, mais uma vez, traz à tona as falas que aparentam ser mais agressivas e tornam 0 debate mais personalizado. Cita-se, como exemplo, a notícia "Discutir biografias é um serviço à democracia", em que 0 biógrafo Edmundo Leite diz ser "uma vergonha que artistas que sofreram com a ditadura defendam uma causa como essa"8.

\section{A variável do provimento de razões trouxe} resultados muito parelhos para as categorias analisadas. Com cinco aparições cada, houve um empate entre posição não justificada e forte justificação, o que indica que os textos tomaram caminhos bem diferentes, ora se aprofundando nas razões, ora apenas mencionando a posição, sem que 0 enquadramento tenha determinado a predominância de um dos estilos.

Não restou comprovado aqui que a cobertura dos periódicos centrada nos acontecimentos particulares e episódicos acarreta no predomínio de infotenimento (ROCHA, 2012), ou seja, um estilo de produção de notícias que prioriza a 
geração de emoções no leitor. Enquanto alguns textos do frame realmente não trouxeram qualquer justificativa para 0 debate e podem ser compreendidos como simples infotenimento, algumas matérias deram espaço para a argumentação ao mesmo tempo em que 0 problema era retratado pelo viés pessoal.

Ainda é necessário ponderar que 0 enquadramento do interesse humano, ao contrário dos enquadramentos conflito e responsabilidade, apresentou outra categoria predominante na orientação para o bem comum: foi a orientação individual ou para grupo. Em "Roberto se diz a favor de biografia não autorizada" ${ }^{\prime}$ o cantor tenta buscar uma solução que agrade a biógrafos e a biografados mas conduz seu raciocínio como se apenas esse grupo de pessoas fosse impactado pelo tema em debate. Já no texto "Leminski não autorizado", há demonstração clara do interesse particular que fundamenta a posição de Alice Ruiz, exmulher do poeta Paulo Leminski, ao proibir a divulgação de uma biografia escrita sobre 0 artista, pois "tudo isso serve para criar uma imagem bem negativa do Paulo"10.

Aqui, o foco no personagem que caracteriza 0 frame interesse humano parece estar relacionado com as razões egoístas ou individualizadas dos envolvidos que são retratados nas matérias. 0 pensamento na coletividade, que deveria caracterizar um processo deliberativo, só é apontado em quatro matérias desse frame nesses casos, é reforçada a menção aos efeitos, na sociedade, das regras sobre a publicação de biografias. Em matéria de 30 de outubro de 2013, após um mês de debate mediado, o grupo Procure Saber posiciona-se como defensor do "fortalecimento de um direito coletivo", em nome "daqueles, homens e mulheres, que não possuem 0 acesso que temos"11.

O frame interesse humano, assim, pode ser destacado por ter permitido que houvesse expressões de respeito explícito, ao mesmo tempo em que concentrou notícias com mera menção aos argumentos opostos e que se detinham em argumentos orientados aos interesses particulares, distanciando-se dos parâmetros desejáveis.

\section{Econômico: homogeneidade nas características}

0 enquadramento econômico foi encontrado como predominante em apenas quatro matérias, mas apresentou características deliberativas muito consistentes. No aspecto da inclusividade, só

Roberto se diz a favor de biografia não autorizada, Folha de S. Paulo, 28 de outubro de 2013.

10 Leminski não autorizado, 0 Estado de S. Paulo, 16/10/2013.

11 Procure Saber recua e defende liberar biografias, 0 Globo, 30/10/2013. 
tiveram voz nessas matérias biógrafos e artistas e familiares. As outras características foram bem definidas: respeito implícito, menção e degradação da posição contrária, relação causal e orientação voltada para 0 particular.

Ao considerar a civilidade, esse frame trouxe apenas matérias categorizadas como respeito implícito. A ausência de desrespeito, nesse caso, é um bom indicativo de que não houve expressões rudes que poderiam surgir em um texto mais dedicado a lucro, dinheiro e royalties. Esse destaque para a remuneração recebida pelos biógrafos e editores, mas que não era compartilhada com os biografados, era sempre visto de maneira negativa pelos participantes, o que acarretou a predominância, na responsividade, da degradação do argumento contrário.

Em provimento de razões, a relação causal da justificativa apresentada era uma decorrência da superficialidade da discussão. 0s artistas retratados desejavam que as leis permitissem-lhes obter porcentagens sobre a venda dos materiais, ao passo que os autores repudiavam a ideia e diziam que 0 lucro lhes pertencia, ainda que não atingisse patamares elevados no Brasil. Portanto, os personagens retratados apenas opinavam se deveria haver divisão da remuneração, sem maior aprofundamento. Em "Ruy Castro diz que pagaria dízimo para escrever sem censura", o texto relata que 0 biógrafo aceita partilhar seu lucro desde que consiga liberdade para escrever, o que é abordado de maneira bem sucinta: "Eles querem o dízimo? Eu pago, desde que não venham querer interferir no resultado", disse o colunista e escritor da Folha Ruy Castro"12.

\section{Já a respeito da categoria da orientação para o}

bem comum, o que se encontrou foi uma orientação voltada para o particular, também explicada pela discussão sobre os eventuais lucros da obra biográfica. 0 interesse da discussão resumia-se à quantidade de dinheiro gerada e a quem ela seria destinada, sem qualquer preocupação com as outras repercussões para a sociedade.

Com características similares em todas as notícias, o enquadramento econômico demonstrou estar presente em textos bem definidos: poucas vozes ouvidas, sem demonstração de respeito explícito ou desrespeito e com degradação da posição contrária, justificação causal e orientação voltada para o particular. Foi essa a tônica desse conjunto, que dialoga com 0 aspecto central do fato que é salientado por esse frame.

\section{Considerações finais}

Embora tenha sido oframe mais constante, 0 enquadramento conflito não teve uma recorrência tão superior à dos outros. Se for 
considerado que 0 tema foi pautado inicialmente a partir das declarações de artistas famosos e que foi esse 0 estopim para a cobertura maciça dos jornais, poder-se-ia imaginar que a disputa entre os personagens fosse predominante na maioria absoluta dos textos. A personalização do tema que é inerente ao conflito acarretaria uma abordagem de mais fácil entendimento para o público leitor, mas, ao mesmo tempo, de superficialização das discussões, que poderiam recair para torcida e antipatia em relação aos retratados.

Ao relacionar 0 enquadramento conflito com as características deliberativas correspondentes, os dados mostraram que, ao menos na cobertura sobre as biografias, não houve uma correspondência total com aspectos negativos da deliberação. No aspecto da inclusividade, o conflito trouxe, ao menos, duas vozes diferentes para apresentar sua visão sobre 0 tema e, assim, cumprir uma das funções que os meios de comunicação podem desempenhar no sistema deliberativo (algo que outros frames não conseguiram).

Mesmo se levarmos em conta a civilidade, a aparição de desrespeito foi mínima no enquadramento conflito, não recaindo as matérias para descrição de ataques ofensivos - algo que, levando em conta as próprias características do frame, poderia estar presente. Tampouco foi predominante, na variável da orientação para 0 bem comum, a preocupação com o particular, que poderia estar mais ligada ao conflito.
No entanto, não é possível esquecer que algumas características que não são compatíveis com 0 ideal deliberativo estiveram presentes nesse frame. Em especial, na responsividade, a degradação da posição contrária foi predominante e levou a discussão para caminhos que não auxiliam no desenvolvimento de um debate centrado em argumentos.

Os dados presentes nesta pesquisa, portanto, não corroboram com a negativização do enquadramento conflito, que por vezes parece subsistir em certas pesquisas de comunicação. Pelo contrário, há pontos positivos no frame do ponto de vista da deliberação, que podem ser explorados pelo jornalismo para conciliar atratividade e profundidade.

\section{0 enquadramento da responsabilidade foi} o segundo mais encontrado e, ao contrário das nuances positivas vistas no frame predominante, não esteve relacionado com características proveitosas para o sistema deliberativo. Ao enfocar o tema a partir da responsabilidade do poder público em resolver a questão, os textos analisados tenderam a ouvir apenas fontes ligadas ao Estado, o que impede a pluralidade de vozes necessárias para o debate deliberativo. Ademais, ele não apresentou dados positivos na responsividade (preponderância da ausência de menção a outros argumentos) e no provimento de razões (ausência de justificativa foi recorrente), o que reforça as dificuldades que o enquadramento responsabilidade apresentou 
frente ao paradigma deliberativo. Foram textos que relataram a tramitação de projetos de lei e de ações judiciais, mas sem se preocuparem em debater as questões pertinentes aos projetos e ações que retratava.

0 interesse humano foi um enquadramento que deixou transparecer a recorrência do interesse individual. 0 frame também foca a personalização do tema, e esse aspecto talvez seja o mais ressaltado dentre todos os outros frames, pois propõe-se a abordar a questão a partir de histórias específicas de determinadas personagens. A pesquisa demonstrou, contudo, que as matérias deram voz a argumentos individualistas e que não se debruçavam sobre 0 impacto na sociedade, negligenciando 0 aspecto coletivo em que a discussão deliberativa deveria estar fundada.

Junto com 0 enquadramento da moralidade, cuja única aparição impede que sejam estabelecidas relações entre os dados, o enquadramento econômico foi de pouca recorrência, com apenas quatro matérias, mas que demonstram uma grande coerência nas características nele presentes. A repetição do respeito implícito (civilidade), degradação da posição contrária (responsividade), relação causal da argumentação (provimento de razões) e orientação individual ou para grupo (orientação para o bem comum) comprovaram que os textos dedicados ao viés financeiro não conseguiram se diferenciar no aspecto deliberativo, trazendo sempre argumentos rasos que atacavam 0 recebimento de valores pelos biógrafos e a ausência de pagamento aos biografados. Essa crítica mútua e sem embasamentos pouco acrescentou no aprofundamento do debate.

É preciso ponderar também que os enquadramentos conflito e interesse humano, que figuraram entre os mais recorrentes, representam critérios de noticiabilidade já apontados pela literatura como importantes para a prática jornalística (vide SILVA, 2005). Dessa forma, a construção do enquadramento de conflito é justificada uma vez que são as rivalidades, as disputas e as brigas entre aqueles que discutiam a liberação ou restrição das biografias que tornaram 0 tema relevante para a produção jornalística. Do mesmo modo, a proeminência dos biografados que participaram do debate e a curiosidade que despertam entre 0 público são critérios que explicam oframe do interesse humano. 0 s benefícios para o debate público da discussão desse tema nos jornais são consequência, portanto, da presença desses critérios de noticiabilidade que justificaram sua cobertura pelo jornalismo.

Não é a mera ocorrência dos frames conflito e interesse humano que implica a qualificação das notícias enquanto sensacionalistas ou de infotenimento. Pelo contrário, o exame das características deliberativas isoladas demonstrou que não 
é a escolha desse frame que determinará uma abordagem rasa, superficial, que quer apenas conquistar uma audiência fácil. A coexistência desses frames, já típicos da produção jornalística, com uma sofisticação de qualidades deliberativas é um objetivo que pode ser atingido sem abrir mão do enfoque para 0 acontecimento episódico.

Mais que isso, a análise dos materiais analisados neste artigo demonstrou que a construção de matérias por meio de narrativas não é característica exclusiva das matérias de interesse humano. Essa estrutura típica de construção textual é compartilhada pelos profissionais do jornalismo e pode ser útil para 0 que se chama de jornalismo hard news, ou seja, notícias vinculadas a política, economia e afins (ALBUQUERQUE, 2000). No âmbito deliberativo, a estrutura narrativa das matérias pode, ainda, servir como elemento atrativo ao leitor, ao apresentar um debate menos enfadonho.

0 que se notou a partir da pesquisa foi que a própria pluralidade de enquadramentos é necessária a um jornalismo que pretenda ser um ator relevante no aspecto deliberativo, com 0 intuito de fornecer visões diferentes aos leitores. Nesse ponto, não há um enquadramento único que possa ser adotado pelas notícias e que consiga abarcar todas as melhores características deliberativas. Cada um trouxe certas qualidades deliberativas, ao mesmo tempo em que foi negativo sob certas categorias da deliberação.
Mais vantajoso é pensar em como o enquadramento está relacionado com determinados aspectos e utilizar esse conhecimento para sofisticar a cobertura realizada. Se oframe responsabilidade esteve associado a poucas características deliberativas, cabe ao jornalismo optar por reduzir a frequência das matérias enquadradas nesse sentido ou até mesmo refletir a respeito e alterar a maneira como os textos desse frame são compostos, concedendo espaço para os aspectos que não foram tão bem destacados.

Futuras pesquisas que podem decorrer deste trabalho podem partir para outros temas, com maior amplitude midiática e social que a discussão das biografias. A comparação acerca de como assuntos diversos são tratados pela imprensa seria uma maneira de permitir estabelecer ilações mais generalizáveis, que poderiam consolidar 0 conhecimento da área (em especial ao dialogar com pesquisas semelhantes realizadas em outros países). Mesmo durante o período eleitoral, a análise do potencial deliberativo dos enquadramentos poderia demonstrar as vantagens e desvantagens dos estilos de cobertura adotados.

Também mostra-se ser importante dar espaço para os portais jornalísticos na internet, tendo em vista a relevância que o jornalismo online ganhou perante os cidadãos. A possibilidade de matérias mais extensas, que podem ser atualizadas ao longo do dia, bem como das caixas de comentários em que 0 leitor tem um espaço para apresentar sua visão sobre 0 conteúdo, podem influenciar as 
discussões sobre o potencial deliberativo das coberturas jornalísticas.

0s resultados desta pesquisa demonstram que ainda há muitos caminhos abertos, para os quais se faz necessária uma investigação consistente sobre o papel da mídia para a consolidação do debate democrático. 0 aprofundamento dos conceitos de deliberação e dos enquadramentos jornalísticos torna-se, portanto, uma maneira eficaz de compreender o papel da deliberação mediada e apontar soluções que resultem em ganhos para o jornalismo e, como consequência, para a democracia.

\section{Referências}

ALBUQUERQUE, Afonso de. A narrativa jornalística para além dos faits-divers. Lumina, v.3, n.2, p.69-91, 2000.

BOHMAN, The coming of age of deliberative democracy. The journal of political philosophy, volume $6, \mathrm{n}^{0} 4$, pp. 400-425, 1998.

CHONG, Dennis; DRUCKMAN, James n. Framing Public Opinion in Competitive Democracies.

American Political Science Review, vol 101, $\mathrm{n}^{0} 4$, pp 637-655, 2007.

COTTLE, Simon; RAI, Mugdha. Between display and deliberation: analyzing TV news as communicative architecture. Media, Culture \& Society, 2006.

DRUCKMAN, James; NELSON, Kjersten. Framing and Deliberation: How Citizens' Conversations Limit Elite Influence. American Political Science Review, vol 47, $\mathrm{n}^{0} 4$, pp 729-745, 2003.

ENTMAN, Robert. Framing: toward a clarification of a fractured paradigm. Journal of Communication, v.43, n.4, 1993.
FRIAS FILHO, Otávio. Sentidos da vida: a gênese da biografia e 0 "eu" fragmentado na modernidade. Folha de S. Paulo, São Paulo. Ilustríssima. 30 out. 2011. p. 4-5. GAMSON, W; MODIGLIANI, A. The changing culture of affirmative action. Research in Political Sociology, vol 3, pp 137-177, 1987.

GASTIL, John; BLACK, Laura. Public Deliberation as the Organizing Principle Of Political Communication Research. Journal of Public Deliberation, n. 4, v. 1, 2007.

GUENDUEZ, A. A.; SCHEDLER, K.; CIOCAN, D. Generic frames and tonality: mapping a polarizing issue in a multifaceted context. European Journal of

Communication, v 31, n. 5, p. 584-599, 2016.

GUTMANN, Amy; THOMPSON, Dennis. Why deliberative democracy? Princeton: Princeton University Press, 2004.

HABERMAS, Jürgen. Political communication in media society: does democracy still enjoy an epistemic dimension? The impact of normative theory on empirical research. Communication Theory, v.16, pp. 411-426, 2006. Structural transformation of the public sphere. Cambridge, Mass: MIT Press, 1991.

HALLIN, Daniel; MANCINI, Paolo. Comparing

Media Systems: three models of media and politics. Cambridge University Press: Cambridge, 2004.

MAIA, Rousiley. Debates públicos na mídia: enquadramentos e troca pública de razões. Revista Brasileira de Ciência Política, v. 2, p. 303-340, 2009. Mídia e deliberação. Rio de Janeiro: Editora FGV, 2008.

MARQUES, Angela. A deliberação a longo prazo no espaço de visibilidade mediada: o Bolsa-Família na mídia impressa e televisiva. Estudos em Jornalismo e Mídia, v.7, n. 2, 2010. 
MARQUES, Francisco Paulo Jamil Almeida Marques; MIOLA, Edna. Deliberação mediada: Uma tipologia das funções dos media para a formação do debate público. Estudos em Comunicação, n $n^{0}$ 7, vol 1, pp 1-28, 2010.

MENDONÇA, Ricardo Fabrino; FREITAS, F. v.;

OLIVEIRA, W. M. Reciprocidade discursiva, enquadramento e deliberação: a consulta pública sobre reforma política da ALMG. Análise Social, v. 211, p. 244-271, 2014.

MIOLA, Edna. Sistema Deliberativo e tensões entre Interesses Públicos e Privados: a criação da Empresa Brasil de Comunicação em debate no Congresso e na Imprensa. Tese de doutorado defendida perante a Universidade Federal de Minas Gerais (UFMG). 2012. PORT0, Mauro. Enquadramentos da mídia e política; in RUBIM, A. A. C. (org.). Comunicação e política: conceitos e abordagens. Salvador/São Paulo, Edufba/ Editora da Unesp, 2004. Mídia e Deliberação Política: 0 Modelo do Cidadão Interpretante. Política \& Sociedade, v.2, n.2, 2003.

RINKE, Eike Marke et al. Deliberative Qualities of Generic News Frames: Assessing the Democratic Value of Strategic Game and Contestation Framing in Election Campaign Coverage. Political Communication, 30, pp 474-494, 2013.

ROCHA, Paula Roberta Santana. Jornalismo de Infotenimento: sensacionalismo, entretenimento e fait divers. Temática, v. 8, n.7, 2012.

SEMETKO, Holli A; VALKENBURG, Patti M. Framing European Politics: A Content Analysis of Press and Television News. Journal of Communication, pp. 93$109,2000$.

SILVA, Gislene. Para pensar critérios de noticiabilidade. Estudos em Jornalismo e Mídia, vol. 2, n. 1, 2005.

SIMON, A.F; XENOS, Michael A. Media framing and effective public deliberation. Political

Communication, vol 17, $\mathrm{n}^{0}$ 4, pp. 363-376, 2000.

TARROW, Sidney. El poder en movimiento: Los movimientos sociales, la acción colectiva y la política . Madri: Alianza, 1997.

VIMIEIR0, Ana Carolina; MAIA, Rousiley Celi Moreira. Enquadramentos da mídia e o processo de aprendizado social: transformações na cultura pública sobre o tema da deficiência de 1960 a 2008. E-compós, v.14, n. 1, 2011.

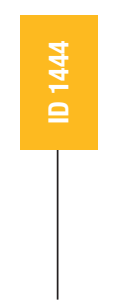




\section{Battle of biographies in the media arena of democracy: frame analysis of journalistic mediated deliberation}

\section{Abstract}

The aim of this article is to analyze how the news frames relate to the deliberative potential of journalistic coverage. As an object, we opted for the debate about the publication of unauthorized biographies, in which a discussion was established on which right should prevail, the freedom of expression of the biographer or the right to privacy of the person depicted in the biography. The corpus includes 56 stories from Folha de S. Paulo, 0 Globo and 0 Estado de S. Paulo. As a methodology, generic frames were adopted - conflict, human interest, economic consequences, morality and responsibility - associated with categories of deliberative potential - inclusiveness, civility, provision of reasons, responsiveness and orientation towards the common good. The relations between frames indicate that the responsibility frame was related to negative characteristics.

\section{Keywords}

News framing. Mediated deliberation. Biographies.

\section{Batalla de las biografías en la} arena mediática de la democracia: análisis de encuadramiento de la deliberación mediada periodística

\section{Resumen}

El objetivo de este artículo es analizar cómo los encuadres noticiosos se relacionan con el potencial deliberativo de una cobertura periodística. Como objeto, se optó por el debate sobre la publicación de biografías no autorizadas, en que se estableció una discusión sobre cuál derecho debería prevalecer, la libertad de expresión del biógrafo o el derecho a la intimidad del biografiado. El corpus engloba 56 materias de Folha de S. Paulo, El Globo y El Estado de S. Paulo. Como metodología, se adoptaron encuadres genéricos conflicto, interés humano, consecuencias económicas, moralidad y responsabilidad -, asociados con categorías de potencial deliberativo - inclusividad, civilidad, provisión de razones, responsividad y orientación para el bien común. Las relaciones entre encuadres apuntan que el encuadramiento de responsabilidad estuvo relacionado con características negativas.

\section{Palabras-clave}

Encuadres noticiosos. Deliberación mediada. Biografías. 


\section{Expediente}

A revista E-Compós é a publicação científica em formato eletrônico da Associação Nacional dos Programas de Pós-Graduação em Comunicação (Compós). Lançada em 2004, tem como principal finalidade difundir a produção acadêmica de pesquisadores da área de Comunicação, inseridos em instituições do Brasil e do exterior.

\section{E-COMPÓS I www.e-compos.org.br I E-ISSN 1808-2599}

Revista da Associação Nacional dos Programas de Pós-Graduação em Comunicação. Brasília, v.21, n.3, set/dez. 2018. A identificação das edições, a partir de 2008, passa a ser volume anual com três números. Indexada por Latindex I www.latindex.unam.mx

\section{CONSELHO EDITORIAL}

Ada Cristina Machado Silveira, Universidade Federal de Santa Maria, Brasi Alda Cristina Silva da Costa, Universidade Federal do Pará, Brasil Alfredo Luiz Paes de Oliveira Suppia, Universidade Estadual de Campinas, Brasil Ana Carolina Rocha Pessôa Temer, Universidade Federal de Goiás, Brasil Ana Regina Barros Rego Leal, Universidade Federal do Piauí, Brasil André Luiz Martins Lemos, Universidade Federal da Bahia, Brasil Angela Cristina Salgueiro Marques, Universidade Federal de Minas Gerais, Brasil Ângela Freire Prysthon, Universidade Federal de Pernambuco, Brasil Anna Cristina Pertierra, Western Sidney University, Austrália Antonio Carlos Hohlfeldt, Pontifícia Universidade Católica do Rio Grande do Sul, Brasi Arthur Ituassu, Pontifícia Universidade Católica do Rio de Janeiro, Brasil Bruno Campanella, Universidade Federal Fluminense, Brasil Bushra Hameedur Rahman, University of the Punjab, Paquistão, Paquistão Cárlida Emerim, Universidade Federal de Santa Catarina, Brasil Carlos Del Valle Rojas, Universidad de La Frontera, Chile Carlos Eduardo Franciscato, Universidade Federal de Sergipe, Brasil Cláudio Novaes Pinto Coelho, Faculdade Cásper Líbero, Brasil Danilo Rothberg, Universidade Estadual Paulista, Brasil Denise Tavares, Universidade Federal Fluminense, Brasil Diógenes Lycarião, Universidade Federal do Ceará, Brasil Dóris Martínez Vizcarrondo, Universidad de Puerto Rico Mayagüez, Porto Rico Eduardo Vicente, Universidade de São Paulo, Brasil

Eliza Bachega Casadei, Escola Superior de Propaganda e Marketing - SP, Brasil Elvira Gomes dos Reis Freitas, Universidade de Cabo Verde, Cabo Verde Eneus Trindade, Universidade de São Paulo, Brasil Erick Felinto de Oliveira, Universidade do Estado do Rio de Janeiro, Brasil Erick Torrico, Universidad Andina Simón Bolívar, Bolívia, Bolívia Erly Vieira Júnior, Universidade Federal do Espírito Santo, Brasil Fabio La Rocca, Université Paul-Valéry Montpellier 3, França Fernando Firmino da Silva, Universidade Federal da Paraíba, Brasil Francisco de Assis, FIAM-FAAM Centro Universitário, Brasil Francisco Elinaldo Teixeira, Universidade Estadual de Campinas, Brasil Francisco Gilson Rebouças Pôrto Junior, Universidade Federal do Tocantins, Brasil Francisco Sierra Caballero, CIESPAL, Equador Frederico de Mello Brandão Tavares, Universidade Federal de Ouro Preto, Brasil Gabriela Reinaldo, Universidade Federal do Ceará, Brasil Germán Rey Beltrán, Universidad Nacional de Colombia, Colômbia Gilson Vieira Monteiro, Universidade Federal do Sul da Bahia, Brasil Gustavo Daudt Fischer, Universidade do Vale do Rio dos Sinos, Brasil Gustavo Hernández Díaz, Universidad Central de Venezuela, Venezuela Heidi Figueroa Sarriera, Universidad de Puerto Rico, Porto Rico Ignacio Aguaded, Universidad Huelva, Espanha Inesita Soares de Araújo, FIOCRUZ, Brasil Itania Maria Mota Gomes, Universidade Federal da Bahia, Brasil Jiani Adriana Bonin, Universidade do Vale do Rio dos Sinos, Brasi João Carlos Ferreira Correia, Universidade da Beira Interior, Portugal Jonathan Cohen, University of Haifa, Israel José Afonso da Silva Junior, Universidade Federal de Pernambuco, Brasil José Luiz Aidar Prado, Pontifícia Universidade Católica de São Paulo, Brasil Josette Maria Monzani, Universidade Federal de São Carlos, Brasil Juçara Gorski Brittes, Universidade Federal de Ouro Preto, Brasil Julián Durazo Hermann, Université du Québec à Montreal, Canadá Juliana Freire Gutmann, Universidade Federal da Bahia, Brasil
Karla Yolanda Covarrubias, Universidad de Colima, México Laura Loguercio Cánepa, Universidade Anhembi Morumbi, Brasil Leonel Azevedo de Aguiar, Pontifícia Universidade Católica do Rio de Janeiro, Brasil Leticia Cantarela Matheus, Universidade do Estado do Rio de Janeiro, Brasil Ling Chen, Hong Kong Baptist University, China Luciana Coutinho Souza, Universidade de Sorocaba, Brasil Marcel Vieira Barreto Silva, Universidade Federal da Paraíba, Brasil Marcia Tondato, Escola Superior de Propaganda e Marketing, Brasil Márcio Souza Gonçalves, Universidade do Estado do Rio de Janeiro, Brasil Maria Ataide Malcher, Universidade Federal do Pará, Brasil Maria das Graças Pinto Coelho, Universidade Federal do Rio Grande do Norte, Brasi Maria Elena Hernández Ramirez, Universidad de Guadalajara, México Maria Elisabete Antonioli, Escola Superior de Propaganda e Marketing - SP, Brasil Maria Teresa Quiroz, Universidad de Lima, Peru Marialva Carlos Barbosa, Universidade Federal do Rio de Janeiro, Brasil Marina Poggi, Universidad Nacional de Quilmes, Argentina Marli Santos, Faculdade Cásper Líbero, Brasil Mateus Yuri Passos, Universidade Metodista de São Paulo, Brasil Mauricio Mario Monteiro, Universidade Anhembi Morumbi, Brasil, Brasil Mayka Castellano, Universidade Federal Fluminense, Brasil Mirta Varela, Universidad de Buenos Aires, Argentina

Mozahir Salomão Bruck, Pontifícia Universidade Católica de Minas Gerais, Brasil Neyla Graciela Pardo Abril, Universidad Nacional de Colombia, Colômbia Nísia Martins Rosario, Universidade Federal do Rio Grande do Sul, Brasil Olga Guedes Bailey, Nottingham Trent University, Reino Unido Paolo Demuru, Universidade Paulista, Brasil

Paolo Peverini, LUISS, Itália

Paško Bilić, Institute for Development and International Relations, Croácia Paula Melani Rocha, Universidade Estadual de Ponta Grossa, Brasil Potiguara Mendes Silveira Jr, Universidade Federal de Juiz de Fora, Brasil Rafael Cardoso Sampaio, Universidade Federal do Paraná, Brasil Rafael Tassi Teixeira, Universidade Tuiuti do Paraná, Brasil Regiane Lucas de Oliveira Garcêz, Universidade Federal de Minas Gerais, Brasil Regiane Regina Ribeiro, Universidade Federal do Paraná, Brasil Renata Pitombo Cidreira, Universidade Federal do Recôncavo da Bahia, Brasil Renato Essenfelder, Escola Superior de Propaganda e Marketing, Brasil Roberto Elísio dos Santos, Universidade Municipal de São Caetano do Sul, Brasil Robson Borges Dias, Universidade Católica de Brasília (UCB), Brasil Rodolfo Rorato Londero, Universidade Estadual de Londrina, Brasil Rosario Sanchéz Vilela, Universidad Católica del Uruguay, Uruguai Roseli Figaro, Universidade de São Paulo, Brasil Saima Saeed, Jamia Millia Islamia, India Sara Brandellero, Leyden University, Holanda Simone Maria Andrade Pereira de Sá, Universidade Federal Fluminense, Brasil Sônia Caldas Pessoa, Universidade Federal de Minas Gerais, Brasil Sun Sun Lim, Singapore University of Technology and Design, Singapura Tatiana Oliveira Siciliano, Pontifícia Universidade Católica do Rio de Janeiro, Brasil Thaïs de Mendonça Jorge, Universidade de Brasília, Brasil Valquiria Michela John, Universidade Federal do Paraná, Brasil Vicky Mayer, Tulane University, Estados Unidos da América do Norte Yamile Haber Guerra, Universidad de Oriente, Cuba 


\section{CONSELHO CIENTÍFICO}

Cristiane Freitas Gutfreind, Pontifícia Universidade Católica do Rio Grande do Sul, Brasil I Eduardo Antonio de Jesus, Universidade Federal de Minas Gerais, Brasil I Eduardo Morettin, Universidade de São Paulo, Brasil I Irene de Araújo Machado, Universidade de São Paulo, Brasil

\section{COMISSÃO EDITORIAL}

Igor Pinto Sacramento, Universidade Federal do Rio de Janeiro, Brasil I Kelly Cristina de Souza Prudencio, Universidade Federal do Paraná, Brasil | Miriam de Souza Rossini, Universidade Federal do Rio Grande do Sul, Brasil

\section{EDITORES ASSOCIADOS}

Rafael Grohmann, Faculdade Cásper Líbero, Brasil I Thaiane Moreira de Oliveira, Universidade Federal Fluminense, Brasil

\section{CONSULTORES AD HOC}

Ada Machado, Universidade Federal de Santa Maria, Brasil | Ana Carolina Escosteguy, Universidade Federal de Santa Maria, Brasil | Andrea França, Pontifícia Universidade Católica do Rio de Janeiro, Brasil | Ariane Holzbach, Universidade Federal Fluminense, Brasil | Benjamim Picado, Birkbeck College, Inglattera | Bruno Souza Leal, Universidade Federal de Minas Gerais, Brasil I Eduardo Morettin, Universidade de São Paulo, Brasil I Felipe Trotta, Universidade Federal Fluminense, Brasil | Francisco Rüdiger, Pontifícia Universidade Católica do Rio Grande do Sul, Brasil | Gislene da Silva, Universidade Federal de Santa Catarina, Brasil | Inês Vitorino, Universidade Federal do Ceará, Brasil I Isaltina Gomes, Universidade Federal de Pernambuco, Brasil I Jairo Ferreira, Universidade do Vale do Rio dos Sinos, Brasil I Karina Janz, Universidade Estadual de Ponta Grossa, Brasil | Kati Caetano, Universidade Tuiuti do Paraná, Brasil | Lilian França, Universidade Federal do Sergipe, Brasil | Liziane Guazina, Universidade de Brasília, Brasil I Márcio de Vasconcellos Serelle, Pontifícia Universidade Católica de Minas Gerais, Brasil I Marta Maia, Universidade Federal de Ouro Preto, Brasil I Maurício de Bragança, Universidade Federal Fluminense, Brasil I Nina Velasco e Cruz, Universidade Federal de Pernambuco, Brasil | Norval Baitello Jr., Pontifícia Universidade Católica de São Paulo, Brasil | Pedro Guimarães, Universidade do Estado do Rio de Janeiro, Brasil | Priscilla Perazzo, Universidade Municipal de São Caetano do Sul, Brasil I Sofia Zanforlin, International Association of Media and Communication Research, Estados Unidos I Talitha Ferraz, Escola Superior de Propaganda e Marketing, Brasil I Tattiana Teixeira, Universidade Federal de Santa Catarina, Brasil I Victa de Carvalho Pereira da Silva, Universidade Federal do Rio de Janeiro, Brasil

\section{EQUIPE DE EDITORAÇÃO}

ASSISTENTE EDITORIAL Marcio Telles I REVISÃO DE TEXTOS Fátima Áli | EDITORAÇÃO ELETRÔNICA Roka Estúdio

COMPÓS I www.compos.org.br

Associação Nacional dos Programas de Pós-Graduação em Comunicação

Presidente

Marco Roxo

Programa de Pós-Graduação em Comunicação - UFF

marcos-roxo@uol.com.br

Vice-Presidente

Isaltina Gomes

Programa de Pós-Graduação em Comunicação - UFPE

isaltina@gmail.com

Secretária-Geral

Gisela Castro

Programa de Pós-Graduação em Comunicação

e Práticas de Consumo - ESPM

castro.gisela@gmail.com

CONTATO I revistaecompos@gmail.com 